\title{
Research on Xun Yunchang's Calligraphy Education Thought and Calligraphy Art
}

\author{
Qiang Sun \\ School of Calligraphy, Zhengzhou University, Zhengzhou 450052, China \\ Email:790662685@qq.com
}

\begin{abstract}
During his lifetime, Xun Yunchang was a professor at the School of Liberal Arts of Southwest University. He was a master tutor for two majors in classical literature and calligraphy. He has made great achievements in poetry and calligraphy. He has three identities as calligrapher, poet, and scholar, showing his profound learning and superb level. Mr. Xun's calligraphy integrates Han and Wei dynasties, and goes in and out of Jin and Tang dynasties, which is thick and steady. Through case analysis and other research methods, this article believes that Mr. Xun has made a great contribution to the cause of calligraphy in China and should have a lofty status in the history of modern calligraphy.
\end{abstract}

Keywords: Xun Yunchang, calligraphy, education, thought

\section{Introduction}

Xun Yunchang grew up in the early years of the Republic of China. At that time, the calligraphy circle was based on returning to "Two Wangs" (Wang Xizhi, Wang Xianzhi). Following the trend of "Two Wangs" prevailing, many calligraphers turned to "Two Wangs". However, Mr. Xun was not moved by the trend, and he was lonely and independent of the times. He tirelessly walked his path of stele studies and became a successor of stele studies in the same line as Qing Dynasty. "Xun was originally a native of Xi'an. He was a young man who was left in exile and went into exile in Yuzhou. He was admitted to Chongqing University and studied under Ai Wu, Shang Chengzuo, etc." ${ }^{[1]}$ His calligraphy was taught by his teacher Shang Cheng Zuo, and he devoted much attention to the Bei Dynasty tablet and Tang Kai. Although he studied steles, his idea of worshipping steles was different from Kang Youwei's. He advocated the inclusive of steles. Mr. Xun insisted on walking his own way, and finally radiated a brilliant brilliance in the calligraphy. In order to cherish the memory of the achievements of the founder of calligraphy education, the author will outline the calligraphy art of Mr. Xun and take it as a memorial. Please make a comment or criticism if it is inappropriate.

In calligraphy education, Xun Yunchang, as the earliest calligraphy master tutor, has cultivated a large number of calligraphy talents. Facts have proved that Mr. Xun's training program is reasonable, scientific and worthy of recognition. $\mathrm{He}$ is one of the founders of Chinese calligraphy education, and he deserves it.

\section{To learn calligraphy, first be a person of high moral character}

In the history of ancient Chinese education, the ideas of "education before teaching" and "being first for art" have always been passed down from generation to generation. From Kang Nanhai's lecture in the "Ten Thousand Wood Cottage", the core of Confucianism was "aspiration, virtue, benevolence, and art" as his academic rules, and then to Chairman Mao, Chen Zan and Cai Yuanpei Mr. is a "academic leader, a role model in the world" ${ }^{[2]}$, it can be seen that most people in the world put moral behavior first. The ancients said that "moral articles spread to the world" also said that the moral character of people should be the first, followed by articles. Many sages and sages in the history of China have been impressed by the world with their noble morals, and their articles and works of art have been famous in history. In the art of calligraphy, "words reflect the spirit of the writer, from which we can judge whether it is a gentleman or a villain." "Calligraphy quality is character", "Calligraphy is like a man" and other past sages' comments all show that the quality of works depends on the evaluation criteria The character of a calligrapher.

The great literary magnates Qu Yuan, Sima Qian, Du Fu, calligraphers Yan Zhenqing, Liu Gongquan, Su Shi, etc. are all loyal and righteous people. The loyalty of these ancients and their excellent works of art correspond to the history of ancient Chinese culture and calligraphy. A valuable legacy was laid.

Xun Yunchang has high attainments in poetry, calligraphy, education, etc. He is a typical scholar-type calligrapher. He knows well that since ancient times, Chinese culture has always put virtue first. "If a person has noble morals, then his achievements will be very high; if a person has poor morals and only rely on superb skills, then his achievements will be 
very low" ${ }^{[3]}$ s morality and art concept, deeply affected Chinese literati for thousands of years. Throughout the history of Chinese calligraphy, there are countless ideas such as "writing a book before being a man" ${ }^{[4]}$, "calligraphy is nothing but a skill, and establishing character is the most important" ${ }^{[5]}$. As Mencius said: "First, set up the heart, an important part of the body, and other minor parts will not be led astray." ${ }^{[6]}$ In the history of Chinese calligraphy, there are many examples of abandoning books due to bad morals. Therefore, Mr. Xun warned the students that character is very important.

Xun Yunchang teaches by precepts and deeds, telling students that they must be a man if they are determined to study. The husband has followed the motto of "famous name, truth-seeking, avoiding flattery, far gang" all his life. His whole life was indifferent to his ambition, and he lived in simplicity. The husband said to himself: "All my life's achievements are just reading and writing." ${ }^{[7]}$ As commented on Mr. Xun in the book "Love for Paintings" edited by Deng Li: "Calligraphy is the love of his life. His characters are like his person, thick and stable. It is a kind of unassuming atmosphere. It's dyeing and accumulation. It's hard to pretend, and it's more tiring to pretend. The words are like the old saying of the man, and Mr. Xun has been taken seriously." ${ }^{[8]} \mathrm{Mr}$. Xun organically integrates real life and artistic career. Although it is not romantic or strong, it is simple.

\section{Copying before creating is the way to learn calligraphy}

Mr. Xun often said when instructing students' calligraphy practice: "You must start with copying." ${ }^{[1]}$ Copying is the basis for calligraphers to learn and a way to understand calligraphy. To learn calligraphy techniques, learners need to copy ancient excellent ink rubbings or rubbings. In the study of calligraphy, it is possible to learn the techniques of calligraphy only on the basis of inheriting the ancients. Only through meticulous copying can one gain a deeper understanding of the advantages and disadvantages of the learned rubbings. Copying, as a means and method of calligraphy learning, is a process that calligraphy learners must go through. However, the ultimate goal of copying is to master the basic skills, widely absorb the advantages of ancient legal notes, and use them for yourself. Therefore, in terms of learning methods, he advocated copying, copying, reading, practicing, and memorizing posts, as well as earnestly studying and not swallowing dates. In order to better understand the structure of calligraphy and the use of pens, learners can "copy" first, because Mr. Xun knows that "copy" can help meticulous and understand the principles of pen gestures. After making progress, you can "create", because Mr. Xun knows that creating can get its structure and the principle of using writing brushes. Then you can "create" to read the post familiarly, including the stippling, structure, brushwork, ink color, emergency, etc. Then come out, so you can get its form and god. At the end of the creation stage, Mr. pointed out: "In the creation of works, we will encounter the problem of 'self-body', that is, everyone who can lift a pen and write has a habit of 'self-body', which is stubborn in calligraphy. Land resists the introduction of new calligraphy styles. The process of copying and learning is the process of transforming the 'self-body', the purification and improvement of the 'self-body'." [1]

On the issue of the order of calligraphy learning, Mr. Xun believes that for learning calligraphy, official script, regular script, and running script are the basis, and they are also popular scripts in the practical field. It will be more effective to write these three scripts well, and then attack the seal script and cursive script. ${ }^{[1]}$ Mr. Xun also put forward his own point of view: "The steps to learn calligraphy is to learn regular script first, and the beginners to learn regular script are mainly from the Tang Dynasty, and also include regular scripts of various families before and after." ${ }^{[1]}$ Mr. Xun said about the Northern Dynasty. The inscription on the tablet is highly praised. He advocates the combination of inscription and inscription when learning calligraphy. Since the Republic of China, the calligraphy thought that "the monument can strengthen its bones, and the post can nourish its spirit" has been widely circulated. Choose the strengths of steles and calligraphy, and combine the thick stippling, stretched structure, and neat and dense composition of steleology with the proficiency of the pen and the vivid charm of the calligraphy. From Mr. Xun's calligraphy works, we can also see his calligraphy education thought that places equal emphasis on rubbings, as is shown in Figure 1 and Figure 2. 


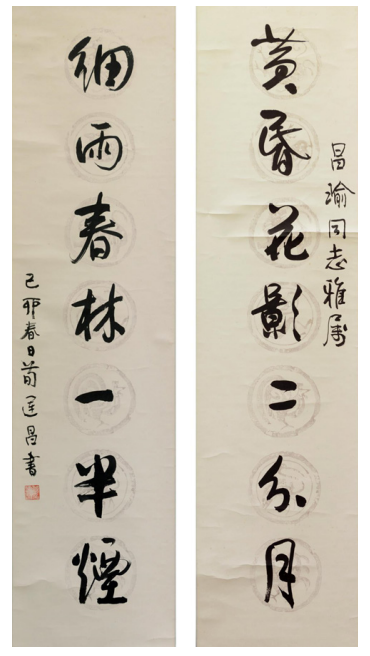

Figure 1. Xun Yunchang's running script No. 1

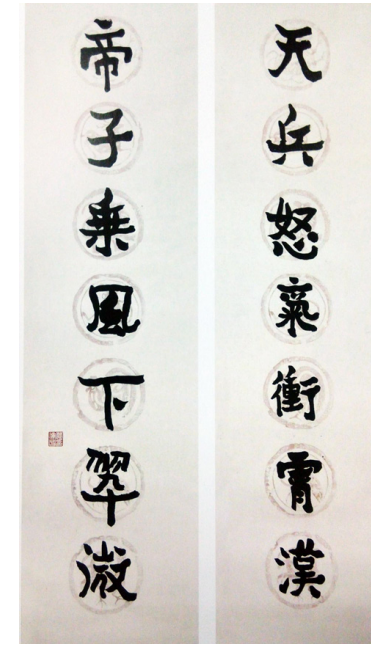

Figure 2. Xun Yunchang's running script No. 2

\section{Solid knowledge is the foundation of calligraphy creation}

There is no uneducated calligrapher in ancient and modern times. When it comes to learning, most people understand it as "learning", and the nine-volume Chinese dictionary does interpret it as "learning". ${ }^{[9]}$ Mr. Xun's calligraphy education thought is to cultivate calligraphy talents with "learning". Mr. Xun once said: "In the traditional culture of the motherland, calligraphy is often related to human knowledge. The so-called 'shujuanqi' and 'guan'ge style' is an illustration of this relationship. Throughout the history of Chinese calligraphy, there is almost no one. A calligrapher without learning and skill." ${ }^{[10]}$ Mr. Xun believed that in order to achieve greater success in calligraphy, he must be based on knowledge. Because the traditional Chinese calligraphy art is not just a pure handwriting skill training, the skill of the technique can only be called a "bookmaker". If you want to train yourself to be a true calligrapher, you must attach importance to and improve your cultural accomplishment.

How to improve the knowledge of calligraphy learners? The first is to improve literary accomplishment. Mr. Xun once said: "In the long-term teaching and research of Chinese classical literature, I have gradually realized the mutual use of Chinese literature and Chinese calligraphy (that is, calligraphy depends on literature to nourish, and literature uses calligraphy to spread)." ${ }^{[10]}$ Therefore, Mr. Xun's calligraphy education thought first advocated "read more and write more". ${ }^{[10]}$ The reading of traditional classic literature has existed in China for thousands of years and has made great contributions to the evolution of Chinese civilization. The reading of traditional literature not only satisfies the advanced spiritual needs of human beings, but also cultivates rich imagination of human beings and stimulates creative thinking of human beings. Many human activities are realized through reading. The process of reading is actually a process of continuous thinking, judgment, evaluation, and imagination. It is a process of deepening and recreating knowledge. It is the main means to increase knowledge and improve cultural cultivation. Mr. Xun deeply understands that the art of calligraphy is about learning and learning at the end. For calligraphers, cultural cultivation is based on the practice and cultivation of the "knowledge" level, after extensive study of literature, history, philosophy, beauty and other traditions. , To further integrate culture into his own calligraphy behavior. Culture is a necessary way for the art of calligraphy to "advance skills as well as Tao". Only in this way can we gather the wisdom of the world and integrate calligraphy. Therefore, Mr. Xun advocated "read more and write more". ${ }^{[10]}$ His own calligraphy practice also proved that his calligraphy education viewpoint is correct. Mr. Xun wrote a lot of poems throughout his life, and he was very knowledgeable. It is this frank mind and tireless pursuit that created his extraordinary artistic temperament, and also created his strong calligraphy artistic achievements. It can be said that he is worthy of being a great scholar in the contemporary Chinese book world.

\section{Take good care of students and teach in accordance with their aptitude}

Mr. Xun is very strict in the teaching process, but he cares and loves students very much in daily life. For some students with difficult families, he often donates school supplies to them, and often encourages them to work hard and learn. For the students who asked him for advice, he always took the trouble to answer their doubts. Mr. Xun has taken teaching work seriously and is responsible to students, which has won unanimous praise from teachers and students. Li Dawu, a student of Mr. Xun, recalled in the article: 
"I remember when I was a junior, reading Wang Mian's "Jing Cao Xing", Lu Yu Mr. Xun asked him for the second half of the will, he deliberated for a moment, and immediately answered, so that my loyal soul and Jingcao contacted, and the cloud was immediately seen. A few days later, Mr. Xun asked his sophomore classmates to send a letter, in small letters to write the origin of 'Jincao' and a deeper understanding of the latter half. The letter is still stuck in the pages of my book, and I understand to be such a teacher." ${ }^{[11]}$

From the above trivial things, we can see that Mr. Xun is dedicated to teaching and responsible to students. He explained what "preaching, teaching, and solving puzzles" is with actions. It is the love and responsibility of the students for 30 years that have made great achievements in the whole garden.

On the other hand, Mr. Xun often teaches students in accordance with their different characteristics. His students once wrote in the article "My Gentlemen": "Mr. Xun is indifferent by nature and loves Zhuangzi. At that time, I did not like to study professional books in the Tang and Song dynasties, and did not like to write academic papers. Instead, I went to read nearly a hundred martial arts books. Novels often have a lot of weird ideas and always write eloquent prose. My husband did not stop me too much, and I finally embarked on the path that suits me." ${ }^{[12]}$ Mr. Xun thinks that students' talents and interests are different, and should be Different guidance is given according to the specific situation of the students. This is also true in the teaching of calligraphy. Only when students are allowed to choose their suitable rubbings for learning, can the learners fit in with them, and then they can achieve the effect of getting twice the result with half the effort, and there is no mandatory requirement.

In short, Xun Yunchang's views on calligraphy are all his experience summed up based on his own practice. Exploring his educational thoughts has important enlightenment for calligraphy teaching in contemporary colleges and universities, and is conducive to the development of contemporary calligraphy education.

\section{Conclusion}

Xun Yunchang's extensive and profound calligraphy quality is just like his character. His character is noble, and his noble character gave birth to his profound calligraphy. Mr. Xun was indifferent to fame and fortune throughout his life, and lived frugally. His life was also quite bumpy, but he continued to improve, worked hard, and dedicated his life to education.

The calligraphy path that Mr. Xun has taken is successful, and his outstanding achievements in calligraphy education are obvious to all. He is the founder and pioneer of Chinese calligraphy higher education. Therefore, he should have a lofty position in the history of modern Chinese calligraphy.

\section{References}

[1] Cao Jian, Zhang Xingcheng, Xun Xiaomei. Tiandiyi Shaou Xun Yunchang Calligraphy Collection. Chongqing: Southwest Normal University Press; 2017.

[2] Zhou Suyuan. Mao Zedong's comment on historical figures of ancient and modern times. Shanghai: Shanghai People's Publishing House; 2012.

[3] [Qing] Zhu Bin. Compilation of Li Ji Xun. Beijing: Zhonghua Book Company; 1998.

[4] [Ming] Fu Shan. Shuanghong Niche Book Theory. In Cui Erping. Ming and Qing Calligraphy Essays. Shanghai: Shanghai Bookstore Publishing House; 1994.

[5] [Qing] Zhu Hegeng. Lin Chi Xin Jie. In Huang Binhong and Deng Shi. Fine Arts Series·First Collection Seventh. Shanghai: Shenzhou Guoguang Press; 1913.

[6] [Song] Zhu Xi. Notes on Chapters and Verses of Four Books·Mencius Gao Zi Zhang. Beijing: Zhonghua Book Company; 1983.

[7] Cao Jian. Miss my teacher, Xun Yunchang, Southwest Normal University Newspaper. 1990; (3): 19.

[8] Deng Li. Love for Paintings. Chengdu: Sichuan University Press; 2011.

[9] Nine-volume Chinese Dictionary Editorial Committee. Chinese Dictionary Chinese History Chronology. Wuhan: Hubei Changjiang Publishing Group Chongwen Bureau; 2010.

[10] Xun Yunchang. How to further study and research calligraphy. Friends of Calligraphy. 2000; (8): 6-7.

[11] Li Dawu. The Big Art without Art — Professor Xun Yunchang's Two or Three Events. Journal of Southwest Normal University. 1990; (3): 19.

[12] Zhou Yu. My Teachers. Journal of Southwest Normal University. 1990; (3): 19. 